\section{Force and Energy}

Your correspondent, Mr. R. H. Smith (Nature, vol, xix, p. 194), speaks of "the fine old crusty Newtonian maxim . . 'force is any CAUSE which,' \&c." Now Newton's words are these: "Definitio IV.-Dis impressa est ACTIO IN CORPUS EXERCITA, ad mutandum ejus statum vel quiescendi vel movendi uniformiter in directum." It will be observed that Newton avoids the use of the obnoxious word CAUSE. I suppose that some translator, or commentator on Newton, adopted the word "cause". (in the sense, probably, not of an efficient cause in itself, but, by a common figure of speech, of the action of some cause); and that other writers transcribed the expression.

Prof. Tait, who is specially referred to by your correspondent, seems to have overlooked the above definition when he wrote ("Recent Advances," ed. i.p. I6): "the definition of force in physical science is implicitly contained in Newton's 'First Law of Motion,' and may thus be given : Force is any cause," \&c. Newton, in that law, speaks of "vires impressæ," but forbears there to define, or explain, "vis." Clearly he refers back to Def. IV., where, as I have shown, he defines "vis impressa" by " actio," not by "causa."

In justice to Prof. Tait, however, it should be pointed out that in the passage referred to he proceeds at ance to discuss the difficulty introduced by the word "cause." He has, in fact, anticipated your correspondent in the idea of his definition of force. Prof. Tait writes thus : "In every case in which force is said to act, what is really observed ... is either a transference or a tendency to transference of what is called energy from one portion of matter to another. Whenever such a transference takes place there is relative motion of the portions of matter concerned, and the so-called force in any direction is merely the rate of transference of energy per unit of length for displacement in that direction."

J. G. H.

\section{Electrical Phenomena}

Mr. GreEn, in his letter to NATURE, vol. xix. p. 220, omits to state the route by which he ascended Monte Rosa " not long since." This is a detail of interest, because the rocks of that range are decidedly magnetic, and much bidden on the north side by ice.

In 1875 , much out of sorts, I was training by short climbs, and at the Kiffleberg, well known for its effect upon the magnet, strolling up the Gorner Grat in company with three other members of the Alpine Club, and several more, the sky quickly clouded over, it thundered, and the axes of the AIpine inen fizzed in most orthodox fashion, especially when held up, and the long sticks of the non-climbing men also crackled. A transitory but vivid lightning storm followed.

Several days later, during an attempt to ascend the Stockhom, in company with a young Englishman, from the north side, by the Triftje glacier, the same fizzing, concurrently with snow, thunder, and lightning, took place, and half up the last glacier a violent storm came upon us, and throwing caution to the winds, we both skeltered down the snow and ice slopes with scant respect for crevasses seen and hidden. But for the nountaineer's axiom, "never part with your axe," we were much inclined to throw ours on one side. Soon we got below this critically charged stratum of air and earth, and the fizzing ceased. I shall never forget that terrible half hcur, only to be imagined by mountaineers or seafarers. Forbes, in his splendid work on glaciers, relates a similar incident somewhere in this same range.

Positive and negative changes of earth and air, conductibility of these and of axes, and involuntary experimenters suggest themselves. In our latter case all were more than damp!

I have not Forbes' book here, and can therefore quote no details. Thunderstorms are characteristic. In 1849 ( $l$ think it was) I made a new pass, called the Neue Weiss Thor. Overhead it was fine. A mile below was a thunderstorm, and during our descent on the Italian side, we came into it, and were refreshed first by snow, then by rain, till we reached Macuguaga. Marshall Hall

Vernex-Montreux, Canton Vaid, Switzerland, January 27

\section{Ear Affection}

SEveral years ago, during an attack of whooping-cough, I found that one of my ears was so affected is to cauce sounds heard by that ear to seem flatter than their true pitch as heard by the other ear. The difference was about a semitone, as I ascertained by holding a tuning-fork to each ear alternately; and when I whistled I heard two notes in discord. The affection lasted about ten days.

Will one of your readers kindly render me an explanation. Adelaide, November, 1878

P.

\section{RELATION OF METEORITES TO COMETS:}

I HOLD in my hand a stone that weighs about two and a half pounds. Over a part of its surface is a thin black crust. . A part of its corners are cracked off, showing a gray interior, and on looking closer you see small points of iron all through it. It is heavy-about one half heavier than granite, or marble, or sandstone. Altogether it is a very curious stone, totally unlike any of our rocks.

\section{That stone was once a part of a comet.}

Do you want my reasons for saying it? Or, does any one doubt it? I propose to-night to give those reasons; to set in order, as clearly and simply as I can, the facts and lines of thought that lead me to say as I did-thit stone was once a part of a comet.

It came to us from Iowa. Three years ago, on February I2, about ten o' clock in the evening, the light of a bright meteor was seen by nearly everybody then in the open air in the south-east part of that state. I will quote from a vivid description of the meteor given by $\mathrm{Mr}$. Irish, a civil engineer of Iowa City, who has collected and published many facts about it : "The observers," he says, "who stood near to the line of the meteor's flight, were quite overcome with fear, as it seemed to come down upon them with a rapid increase of size and brilliancy, many of them wishing for a place of safety, but not having the time to seek one. In this fright the animals took a part, horses shying, rearing, and plunging to get away, and dogs retreating and barking with signs of fear. The meteor gave out several marked flashes in its course, one more noticeable than the rest. . . . Thin clouds of smoke and vapour followed in the track of the meteor. . . . From one and a half to two minutes after the dazzling, terrifying, and swiftly moving mass of light had extinguished itself in five sharp flashes, five quickly recurring reports were heard. The volume of sound was so great that the reverberations seemed to shake the earth to its foundations; buildings quaked and rattled, and the furniture that they contained jarred about as if shaken by an earthquake; in fact, many believed that an earthquake was in progress. Quickly succeeding, and blended with the explosions, came hollow bellowings and rattling sounds, mingled with clang, and clash, and roar, that rolled away southward, as if a tornado of fearful power was retreating upon the meteor's path."

From accounts collected from eye-witnesses by Prof. Leonard and $\mathrm{Mr}$. Irish, I conclude that the meteor when first seen was not less than sixty miles high over Northern Missouri; that it descended at an angle of about $25^{\circ}$ with the horizon, in a right line, and disappeared at a height of five or ten miles. Those in the east, as at Kiokuk, saw it low in the west. From St. Louis it was seen in the north-west. In the western part of Iowa it was seen to pass north across the eastern sky. 'To persons in the north it passed straight down on the southern sky, while to those under the path named it passed nearly overhead, rising in the south and south-west and descending in the north north-east. The path thus determined is at least 120 miles long, and was passed over in a few seconds, probably not over ten. The country near the explosion was prairie or alluvial, where stones on the surface are rarities, and about 800 lbs. of stones like this one, nearly 200 in number, have been picked up in a region seven miles by four, a little east of the end of the

I A lecture delivered in the Mechanics' Course at the Sheffeld Scientif.c Sciool cf Yale College, U.S., by Prof. H. A. Newton. 
meteor's path. These are all supposed to come from the meteor. Some were picked up on the surface of the frozen ground. One was found on the top of a snowbank, and about forty feet away were marks of a place where it had first struck the ground. Some were ploughed up in the spring. The two largest found, of 74 lbs, and $48 \mathrm{lbs}$., fell by the roadside, and a law-suit to settle whether they were the property of the finder as being wild game, or of the owner of the lands adjacent as being real estate, was decided in favour of the owner of the land.

No one saw this stone come from that meteor. But in many cases peculiar stones very like to this one have been seen to fall from meteors, and this is one of a group of about twenty stones belonging to Yale College which were gathered at the places and directly after the time of the fall. They are in the Peabody Museum in a case by themselves, and are about one-tenth of all that has been found.

But though we have no eye-witnesses to speak of its fall and finding, the stone as we look at it tells its own story. This rounded side is not waterworn. From your seats you cannot see them, but over these rounded hills and down these valleys run streaks showing that melted matter has flowed over them. On two of the smaller sides is collected a real lava deposit, giving in smallest miniature the twisted gnarled forms that some of you have possibly seen in the large lava beds at the foot of the cone of Vesuvius. This other surface had just begun to be melted, as though the fracture that formed it had been made late in the meteor's flight. This larger face is only smoked, and we might even doubt whether the stone had not been broken here after its fall. But the rounded edges of the thin black crust at the angles of the stone show clearly that, except perhaps at some of the corners, the stone was in its present shape when it struck the ground.

Now what caused that brilliant light, that terrific explosion which was heard for forty miles around, that rain of stones? The only explanation which we can admit is that a stone weighing not less than 800 lbs.--how much more we know not-perhaps two, perhaps fifty times as much, came into the air from without.

What ought to happen upon the passage of such a stone through the air? At the height of thirty to eighty miles, the region where the meteor-tracks are most frequently seen, the air is very rare, rarer than in the socalled vacuum of an air-pump. Yet the rapid velocity of the stone condenses the air in front of it. If we admit the truth of the kinetic theory of gases we must regard the molecules of air as in rapid motion, each molecule driven this way or that, coming in contact with and bounding back from other molecules. The average velocity of these dancing molecules of air at usual temperatures is a fraction of a mile per second. They therefore bound back from any heavy body that moves only a $f \in w$ hundred feet per second, only slightly checking its velocity. But the air is here met by a stone moving, say, fifty times as fast as the average molecule. The molecules are driven together beyond the possibility of getting away, until the temperature of the air is raised enormously. Probably the air is liquefied by the pressure, and then pushed aside by main force till the meteor has passed, when it is driven back again into the vacuum behind, giving us a flame shaped like that of a candle.

What effect has all this on the stone? It is solid and firm, as you see, and can withstand not a little pressure. It is not, therefore, heated within; but on the outside it is in contact with, or rather rubbed hard against, an intensely hot stratum of air. It is therefore melted off just as a piece of tallow would be melted if drawn across a white hot iron. There is no time for the heat to pass by conduction deep into the stone. The melted matter is wiped off by the air. A part clings to these hinder faces of the stone, but the far greater portion helps to make up the meteor's train. It is scattered in eddying currents in a long, narrow, whitish cloud, at first straight, then twisted. That cloud broadens and floats away in contorted forms, remaining visible sometimes a second, sometimes an hour even. The pressure and the heat generally keep cracking the stone, just as any stone is cracked by pressure or when thrown into a hot fire. Parts may survive this treatment and reach the ground. Those who have picked them up as they fell have generally said they were hot, as they must be on the outsitle. But some have been found, it is said, that were very cold. This, too, we may well believe, for they should retain in their interior the intense cold of space.

This stone in my hand shows the breaking up, one fracture being very clearly more recent than another, and if you were near me you might even see fractures that were begun but not ended when the stone reached the ground.

We often see this breaking up. On the wall is a picture of the principal explosion of the Iowa meteor, as given by one who saw it, representing, it may be, the cracking when this fragment was broken off from the main mass. There is also one of a meteor seen in Greece in 1863 by Dr. Schmidt. He was standing on the roof of his house in Athens when he caught sight of a magnificent fireball, moving so slowly that he was able to turn his telescope upon it. The head had two main parts, which were chased by a motley troop of followers, each drawing a bright line on the sky, all of which, at a distance of three or four degrees, melted into a reddish cloud of light. Often a meteor is to the naked eye made up of a group of smaller ones, the whole being like a flock of birds.

I have traced back the history of this stone to its entrance into the air on February I2, 1875, when it was part of a mass not less than two feet, and I suspect not more than ten feet each way. It looked larger, but men saw the flame around the stone, not the stone itself. By itself, and strictly taken, this history has gaps; but taken along with the history of like stones and meteors that are numerous in the records of science, the story is easily filled out as I have given it above. No scientific man today would question it.

The next step in my argument, though admitted by most, is not admitted by all of those whose opinions in this matter are entitled to special respect. I am not aware, however, that anybody has given any formal reasoning against it. I claim that between this stoneproducing meteor of Iowa and the faintest shooting-star which you can see on a clear night in a telescope there is no essential difference as to astronomical character. In all their characteristic phenomena there is a regular gradation in the meteors from one end of the line to the other. They differ in bigness, but in their astronomical relations we cannot divide them into groups. They are all similar members of the solar system.

To prove this we must of necessity rehearse the points in which the large and small meteors are alike and unlike.

First. They are all solid bodies. The Iowa meteor sent down these stones, and we know that they are solid. This other stone which I show you is one of about 4,000 which fell from a meteor in Poland in 1868, and this you can see is solid. In the Peabody Museum is a goodly collection of such stones from other meteors.

A year ago last December, early on the evening of the 2rst, a meteor entered the air sixty miles or more in height over the north-west corner of the Indian Territory, or it may be still farther west. It crossed at a height of between sixty and thirty miles the states of Kansas, Missouri, Illinois, Indiana, and Ohio and passed on over Lake Erie and the state of New York. No sound was heard, so far as I know, in the state of Kansas; but in Missouri, and still more, in Illinois, the explosions were 
fearful, and multitudes of fragments were seen to fly off by every one who saw the meteor. In Indiana it was thought that the explosions were heard at Bloomington I 50 miles from the nearest point of the path. In New York State the sky was wholly overcast, so that of course nothing was seen. But at many places the people thought there was an earthquake. Was this a solid body? As if to remove this from the class of detonating into that of stone-producing meteors, one single small fragment three-fourths of a pound in weight, was heard to fall and was picked up the next morning on the snow in Indiana. A piece of this is in the Peabody. Museum.

In 1860 a meteor went north-west across Georgia and Tennessee and exploded, disappearing nearly over the southern boundary of Kentucky at a beight of about twenty-eight miles. There was the same terrific explosion heard, the same scattering of fragments seen. The meteor was seen over all the region from Pittsburgh to New Orleans, and from Savannah to St. Louis. But from this meteor no stone was found, but you cannot doubt for all that that it was a solid body.

So, a few weeks ago a meteor fell in broad daylight in Southern Virginia, the sound of which, over a limited region, seemed like an earthquake. It, too, must have been solid.

In July, I860, some of you, I presume, saw a meteor cross from the west to the east. It came from over Northern Michigan, and was seen until it had passed at least 200 miles east of us, passing between us and New York City at a height of a little more than forty miles. One pear-shaped ball chased a second and a third across the sky. People listened for the sound to come, and one or two thought that they heard it but would not affirm that it was sound from the meteor. I cannot doubt that that too was solid. It was seen to break in two, and the parts passed on one after the other for hundreds of miles. To be sure no stone was found from it, and perhaps no sound heard, yet that it was solid seems to me almost as sure as if $I$ had a piece of it in my hands.

Again, going one step farther, how can we avoid calling all the meteors solid which are seen to break into pieces, and all those which glance, describing a curved course, or a course having an angle? The number of such cases is large, and often they are very faint shooting-stars. But it is doubtful whether a small gaseous mass could exist permanently as a separate body in the solar system. Its repulsion would keep the parts so far asunder that the sun's unequal attraction would scatter the substance beyond all its own power of recovery. A liquid would probably freeze and become solid. In any case neither a gas nor a liquid could for an instant sustain the resisting pressure which a meteor is subjected to in the air, much less could it travel against it ten, or forty, or a hundred miles. In short, every shooting-star must be a solid body.

Second. The large meteors and the small ones are seen at about the same height from the earth's surface. The larger meteors may become visible a little higher than shooting-stars, though that is doubtful; they come down in general a little lower, some of them even come to the ground, but that is due rather to the size of the body. The air is a shield to protect us from an otherwise intolerable bombarding. Some of the larger balls come through that shield, or, at least, are not all melted before their final explosion, when the fragments, their original velocity all gone, fall quietly to the ground. The small ones burn up altogether, or are scattered into dust.

In the third place, the velocities of the large and small meteors agree. These velocities are never very exactly measured directly; but we are sure that in general they are more than two and less than forty miles per second. This is true both for small and for large meteors. The average velocities for each class are not widely different.

We sometimes need a name for the small body that will, if it should come into the air, make a shooting-star or larger fireball. We call such a body a meteoroid. Now, velocities of from ten to forty miles a second imply that the meteoroids are bodies that move about the sun as centre, or else move through space. These velocities, as well as other facts, are utterly inconsistent with a permanent motion of the meteoroids about the earth, or with a terrestrial origin, or with a lunar origin.

Fourth. The motions of the large and small meteors, as we see them cross the sky, have no special relations to the ecliptic. If either the one or the other kind had special relations to the planets in their origin or in their motions we should have reason to expect them, if not always, at least in general, to move across the sky away from the ecliptic. But the fact is otherwise. We see both small and large meteors move towards the ecliptic as often as from it. Neither class seem, therefore, to have any relation to the planets.

Again, in general character the two classes are alike. They have like varieties of colour, they have similar luminous trains behind them; in short, we cannot draw any line dividing the stone-producing meteor from the shooting star, at least in their astronomical relations. We cannot say that the Iowa meteor is different from the Georgia meteor of 1860 , on the ground that stones were found in one case and not in the other; or that the meteor of December, 1876 , was different from that of July, 1860 , on the ground that one had a series of terrific explosions and the other was only seen to break into parts; or that the meteor that is seen to break into parts differs from one evidently solid, that burns up without any appearance of explosion. They all are astronomically alike. They differ in bigness; but this has nothing to do with their motion about the sun or in space.

When, therefore, we learn something about the origin and motions of the smaller meteoroids, we can infer like facts about the larger ones. I propose, then, to show that shooting stars were once pieces of comets.

(To be continued.)

\section{A ZOOLOGICAL LABORATORY}

PROF. ALEXANDER AGASSIZ, in his Report to the President and Fellows of the Harvard College Museum for 1877 and 1878 , to September 1 , gives an account of his new laboratory at Newport, a plan of which he has been good enough to send us. This is the first report which has been presented since the Museum has come under the care of the President and Fellows of Harvard College, and the description given by Prof. Agassiz sufficiently indicates that the Museum is a model of its kind. During the past eighteen months increased funds have been placed at the disposal of the Museum, and excellent use has been made of them. Not only is the Museum arranged so as to make it of the greatest service to students, but in such a way that the portion thrown open to the public must have an excellent educational effect. Everything has been done to make visitors clearly understand what they see, and evidently this attention is appreciated and is answering its purpose.

The new laborat ory, erected by Prof. Agassiz at his own cost, and which is a model of what such a place should be, is described by Prof. Agassiz as follows :-

The new laboratory erected by me at Newport is twentyfive feet by forty-five. The six windows for work are on the north side, and extend from the ceiling to within eighteen inches of the floor. In the spaces between the windows and the corners of the building are eight worktables, three feet by fire, covered with white tiles, one foot of the outer edge being covered, however, with black tiles for greater facility in detecting minute animals on a black background. Between the windows, movable brackets with glass shelves are placed; while similar 